\title{
Development of a Core Set of Outcome Measures for Use During Treatment of Children With Idiopathic Toe Walking: A Delphi Study and Online Parent Survey
}

Kelly Gray

Macquarie University

Verity Pacey

Monash University

Antoni Caserta

Monash University

Desiree Polt

Consumer

Cylie M Williams ( $\sim$ Cylie.williams@monash.edu )

Monash University

\section{Research Article}

Keywords: Delphi technique, idiopathic toe walking, outcome measures, gait, consumer, ankle, foot

Posted Date: November 8th, 2021

DOI: https://doi.org/10.21203/rs.3.rs-1030167/v1

License: (c) (i) This work is licensed under a Creative Commons Attribution 4.0 International License.

Read Full License 


\section{Abstract \\ Introduction}

There is diversity in outcome measures used during monitoring and treatment of the exclusionary diagnosis idiopathic toe walking (ITW) in children. This diversity makes synthesis of treatment effects difficult. The primary aim of this research was to develop a core set of outcome measures identified by health professionals for use when undertaking treatment with children who have ITW. The secondary aims were to understand if parents agreed with this core set, and if parents believed they could undertake any of these measures in the absence of the clinician.

\section{Methods}

Study 1 was the development of consensus and agreement through the modified Delphi technique with 10 expert health professionals. The first round gathered questions and assessments for consensus, the second and third round enabled agreement with these questions and assessments. Study 2 was an online survey where parents of children who toe walked were invited to provide opinions on the importance of these measures and if they believed they may be able to collect the data about their child without the health professional being present.

\section{Results}

Ten health professionals provided 21 questions and assessments in Round 1 to measure treatment effectiveness for ITW in children. Following consensus and agreement by health professionals over the three rounds, there were nine questions and assessments presented to parent participants in Study 2. There were 34 parents who provided information about their satisfaction with toe walking assessments and treatments. There 27 parents provide detailed responses about the outcome questions and assessments, most parents in support of the core set identified by the experts. Parents also expressed a willingness to self-complete questions or be taught assessments to monitor their child's progress.

\section{Conclusion}

This research developed a core set of questions and measures clinicians, and researchers could implement during health care provision and any research of children with ITW. Use of these measures will enable consistent data collection regardless of the setting and provide the foundation for large data pooling in future treatment research.

\section{Background}


Idiopathic toe walking (ITW) is an exclusionary diagnosis, given when children display an absence of heel strike throughout the stance phase of gait [1]. The severity of toe walking height varies from a mid-foot strike at the start of stance phase, to weighting bear solely through the metatarsal heads throughout the whole gait cycle [2]. The prevalence of idiopathic toe walking is estimated to be $5 \%$ of healthy children, with presentations in both sexes [3]. Research about idiopathic toe walking is commonly grouped into studies trying to understand why the gait pattern occurs, or studies into treatment effectiveness when the gait pattern persists [4]. ITW has associations with sensory challenges [5-7], tight tendoachilies/gastrocnemius and soleus complex [8] and gross motor impacts [6, 9]. Researchers are starting to debate that the presence of any of these features cast doubt on the gait pattern being idiopathic in nature [9]. Yet outcome data supporting many constructs other than ankle range of motion or toe walking presence, are not commonly considered when recording treatment success [1].

Interventions used during treatment of ITW are varied across countries and professions, including conservative (e.g., observation or inactive treatment [10], serial casting [8], or different types of orthoses $[11,12])$ or surgical (e.g., lengthening of the Tendo Achilles [13]) treatments. These treatment methods may be used in isolation or in combination (e.g., surgical intervention with follow-up ankle foot orthoses use compared to serial casting only approaches). Yet these treatments lack high quality trials supporting their implementation and are commonly subject to recruitment and limited follow up timeframe bias [1, 14]. The primary outcome measures of many of these studies are ankle range impairment data or some form of measurement of the height of toe walking, together with any adverse treatment impacts such as skin blisters [1].

A recent systematic review identified 27 diverse types of outcome questions or assessments used in studies about ITW [4]. These outcome measures ranged from simple and inexpensive clinical measures (e.g., ankle range of movement testing) to complex and technically based data collection (e.g., laboratorybased gait analysis). Furthermore, this review reported including many studies with limited reliability and validity of the cited assessments. Yet when children continue to toe walk after treatment, and clinicians continue to apply these similar treatments [15], the definition of toe walking treatment success may need to be revisited and refined. Outcome measures commonly collected may not fully identify where gains have been made during treatment. For example, if the outcomes clinicians are collecting are actually valued by individuals and their families and tell the full story of any treatment successes.

Developing consensus-based core sets of reliable and valid outcome measures are becoming commonplace for many childhood conditions such as Charcot Marie Tooth Disease [16] or Juvenile Idiopathic Arthritis [17]. Core sets of outcome measures enable clinicians to collect data across different healthcare settings to understand meaningful clinical outcomes, and for researchers to collect consistent data to evaluate treatment effectiveness. A set of core set of outcome measures does not exist to understand treatment effectiveness in children with ITW.

Therefore, the primary aim of this research was to develop a set of core outcome measures identified by expert health professionals for use when monitoring or undertaking treatment with children who have 
ITW. The secondary aims were to understand if parents agreed with this core set, and if parents thought they could answer any questions or perform any of these outcome measures with training in the absence of the clinician.

\section{Methods}

Research methodology was approved by The Sydney Children's Hospital's Network Human Research Ethics Committee (LNR/15/SCHN/296) and Monash University Human Research Ethics Committee (30310) with no deviation to set protocols. This research comprised of two studies with different methodologies. Study 1 used an online modified Delphi technique to gain consensus and agreement on the core set of outcome measures. Study 2 was an online survey of families with lived experience of treatment from health professionals for their children's toe walking gait. Both studies were performed in accordance with relevant guidelines and regulations. All participants provided written informed consent through either return of a paper consent form or through indication on an online check box.

\section{Participants}

Study 1 participants were Australian health professionals with identified expertise in assessment and treatment of children with toe walking gait. Expertise was considered by the investigators as additional training (such as medical fellowships or credentials received through peak health professional bodies), holding a senior position with a children's hospital in a team providing treatment to children with toe walking gait or leading research specific to toe walking gait, and published in the past five years.

Study 2 participants were parents or primary care givers of children, and the children had been treated for toe walking gait within the past six months.

\section{Procedure}

Study 1 potential participants were identified through hospitals, health professional department networks, and recent publications found by the research team google scholar. Potential participants were sent individual email invitations. Following return of a signed consent form, participants were provided with a unique number to link responses, and a survey link to complete the online Round 1 of the Delphi survey. This purpose-built survey was trialed prior to use with two health professionals that were not invited to participate, and wording modified as suggested (Appendix 1). Participants were asked their qualifications, profession, gender, recency of practice, practice settings, asked to estimate the percentage of children they worked with clinically, or during research (compared to adults), and an estimated number of children treated annually who had ITW. Participants were continually reminded of the research aim relating to treatment outcome measurement rather than diagnosis, to minimise statements relating to investigations that aid condition specific diagnosis (e.g., medical imaging), or to focus on treatment outcomes relating to ITW, to minimise mention of assessments specific to other conditions known to cause toe walking such as spasticity. 
Participants were guided through a series of multichoice and open-ended response boxes about the types of questions they asked parents during treatment. Survey logics were used when a participant indicated in a multichoice box response (e.g., when the participate identified pain as a question domain), they were then asked to specify how that data should be collected. Participants were also provided free text for additional questions that did not align to domains. Participants were then asked to describe physical assessments used to understand treatment success, with domains aligning to joint ranges of motion, balance, gait, strength. Again, participants were able to select none of those domains or provide further details if they collected different measures. Where a domain was chosen, they were asked to specify how that information was collected from the child.

Where $70 \%$ or greater participant responses in Round 1 were similar, these statements were accepted. Consensus responses were fed back to participants in Round 2 for confirmation on wording or display of any scale. Questions or assessments described by $50-69 \%$ of participants were refined and re-presented to participants in Round 2 for agreement rating. Where questions or assessments were described by less than $50 \%$ of participants, they were discarded.

In Round 2, participants were asked to provide agreement on the generated statements using a 5-point Likert scale (Strongly Disagree, Disagree, Neutral, Agree, Strongly Agree). Participants were also requested to comment about question phrasing. Similar to Round 1, any questions or assessments with $70 \%$ or greater agreement were included within final core set. Questions where $50-69 \%$ of participants agreed were re-phrased based on any feedback and re-presented to participants in Round 3. Any questions were less than $50 \%$ agreed were removed. This process was replicated in Round 3 and any outstanding questions meeting 50-69\% agreement at the end of Round 3 were presented to parent participants in Study 2 , and questions $50 \%$ or less were removed.

In Study 2, a purpose-built online survey (Appendix 2) was advertised through social media, online parent forums and through clinical networks of authors to pass on to potential participants. Parents of children who toe walked from any reason, were invited to provide online feedback on what outcome questions and assessments were important to them during toe walking treatment.

Parent participants were initially asked about which country they lived in, their relationship to the child who toe walks, how many children ( $<18$ years) were in the family, how many children ( $<18$ years) toe walked, reason given by health professional for toe walking gait, health professional/s accessed for treatment within past six months, overall satisfaction with questions and assessments about treatment and toe walking treatments offered, refused, or recently undertaken.

The online survey displayed the questions or assessments developed in Study 1 to parent participants. Survey logic supported parent participants to indicate importance of each question or assessment based on their treatment experiences. Where a parent provided a response of "not at all important" or "slightly important', they were asked why, then presented with the question or assessment developed in Study 1 and asked to indicate agreement with it being used given the expert health professionals found this important. 
Where parent participants responded "moderately important" or "very important' to a question or assessment, they were presented with how it was described in Study 1 and asked the four questions of the validated Intervention Appropriateness Measure (IAM) [18]. Parent participants were also asked to indicate their level of agreement in their own ability to answer the question without a health professional being present for coaching purposes or if they could be taught to take the measurement without the health professional being present. Parent participants were provided with open-ended questions to provide further information if there were additional questions or assessments, they considered important.

\section{Analysis}

Descriptive statistics and analysis of responses of both Study 1 and 2 were undertaken in Microsoft Excel 2018 (Microsoft Corp, Redmond Washington). The authors made a priori decision in Study 1 to recruit 10 experts and that the Delphi would conclude if the total participant response rate dropped below $70 \%$, or at the end of Round 3, irrespective of agreement.

Study 2 data were cleaned for partial responses and only retained in analysis if the minimum data provided both demographic information and satisfaction with questions and assessments. Qualitative responses were themed against the question or assessment domain. This was done by a single researcher with (CW) with an additional researcher's oversight as required (VP).

\section{Results}

There were 14 health professionals identified by the team with expertise in paediatric neurology, orthopaedic surgery, physiotherapy and podiatry. Health professionals were sequentially invited until 10 agreed to participate in Study 1. These health professionals included one orthopaedic surgeon, four physiotherapists and five podiatrists, all completed the three rounds. There were seven participants identify as female (70\%), six (60\%) had 11 or greater years of clinical experience, eight (80\%) were currently enrolled or had completed a higher degree by research or coursework with a substantial component being paediatric related. The median (interquartile range) percentage of children in their case load was $82.5 \%$ (65-100\%) and six (60\%) participants treated between 10-50 children annually with ITW, two $(20 \%)$ treated $>51$ children with ITW annually.

\section{Consensus}

Round 1 took participants approximately 40 minutes to complete. Participants generated 21 statements about questions and assessments to understand the impact of treatment for toe walking gait. Questions reaching consensus in Round 1 were related to gait (the presence of toe walking) and pain (amount of pain using a visual analogue scale). Participants reached consensus that ankle range of movement should be assessed, but not on how this assessment should occur. Similarly, participants reached consensus the clinical observation of gait should consider strength and ankle range of movement, but not how this could be collected or quantified in the absence of gait analysis equipment. Table 1 presents 
all statements generated by participants, and the frequency of participants who provided the same response.

\section{Agreement}

Round 2, took most participants (90\%) less than 10 minutes to complete and in Round 3, all participants took less than 5 minutes to complete the survey. Table 1 provides the statements from Round 1 progressing to Rounds 2 and 3 using the same frequency coding system as Round 1. In Round 2, adherence to recommended treatments, ankle range of motion measures and clinical gait measures were presented to participants. The authors provided peer reviewed published information about methods for measuring ankle range of motion $[19,20]$ to support participants decisions on which ankle range of motion measurement they agreed most with. Authors also used the statements provided in Round 1 to develop and present a pictorial clinical gait scale using a numerical rating of 0-4 (Figure 1) with varied heel position and forefoot during 10 steps. No questions were discharged from Round 3.

A proforma was developed for Study 2 consisting of visual analogue scales relating to the amount of toe walking during the week, satisfaction with treatment, adherences to treatment plan and pain on day of assessment and pain during activity in the prior week. Measures included two ankle range of motion measurement techniques. While the weight bearing lunge test was considered as the most reliable when the child was able to place their heel on the ground, the non-weight bearing ankle range of motion measure was referenced when this was not possible. The 6-minute walk test was considered by health professionals as useful as per protocol [21], without consensus on how often it should be collected during the treatment journey. 
Table 1

Statements developed and accepted through Delphi rounds.

\section{Statement Method}

Round

1

Round 2

Round

3

\section{Questions asked of the parent and/or child}

Toe walking Reported by parent/child using percentage of

presence time on toes or a binary yes/no

$90 \%$

Taken

to

parent

survey

Pain

Report by parent/child using age-appropriate

$70 \%$

Taken

presence

VAS on day and over the week

to

parent

survey

Treatment

Measured by \% of week or days of the week the

$60 \%$

$50 \%$

$50 \%-$

adherence

treatment was followed through log or star chart

Taken

to

parent

survey

Satisfaction Satisfied with treatment approach

$70 \%$

Taken

to

parent

survey

\begin{tabular}{lll} 
Injury & Number of injuries associated with gait pattern & $10 \%$ \\
$\begin{array}{lll}\text { Toe walking } \\
\text { impact }\end{array}$ & Shoe wear & $20 \%$ \\
\hline
\end{tabular}

\section{Assessments performed by the clinician on the child}

Ankle range No specific method

$70 \%$

Taken

of motion

to

parent

survey

Ankle range Weight bearing lunge test [19]

$60 \%$

$80 \%$

Taken

of motion

to

parent

survey

Ankle range

Non-weight bearing goniometry with leg straight

of motion

and knee bent [22]

$60 \%$

Considered

Taken

on a clinical

to

basis if a

parent

child is

unable to put

survey

heel to

ground

Knee range Hamstring length

$10 \%$

of motion 


\begin{tabular}{|c|c|c|c|c|}
\hline Statement & Method & $\begin{array}{l}\text { Round } \\
1\end{array}$ & Round 2 & $\begin{array}{l}\text { Round } \\
3\end{array}$ \\
\hline \multirow[t]{7}{*}{ Gait } & $\begin{array}{l}\text { Responses describing the ability to heel walk } \\
\text { combined with the strength of ankle dorsiflexor } \\
\text { muscles with consideration of timing such as } \\
\text { the 6-minute walk test (6MWT) [21]. }\end{array}$ & \multirow[t]{7}{*}{$60 \%$} & \multirow[t]{7}{*}{$90 \%$} & \multirow[t]{7}{*}{$\begin{array}{l}\text { Taken } \\
\text { to } \\
\text { parent } \\
\text { survey }\end{array}$} \\
\hline & $\begin{array}{l}\text { Scale presented in Round } 2 \text { for } 10 \text { steps prior to } \\
6 \text {-minute walk test: }\end{array}$ & & & \\
\hline & $\begin{array}{l}0 \text { - Unable to get heel or mid foot to ground. } \\
\text { Walks on metatarsal heads }\end{array}$ & & & \\
\hline & $\begin{array}{l}1 \text { - Unable to get heels to ground. Midfoot strike } \\
\text { present. }\end{array}$ & & & \\
\hline & $\begin{array}{l}2 \text { - Able to get heels to ground. Unable to walk } \\
10 \text { steps with great toe dorsiflexed }\end{array}$ & & & \\
\hline & $\begin{array}{l}3 \text { - Able to get heels to ground and walk } 10 \text { steps } \\
\text { with great toe dorsiflexed. However, plantar } \\
\text { surface of forefoot remains on ground. }\end{array}$ & & & \\
\hline & $\begin{array}{l}4 \text { - Able to get heels to ground and walk } 10 \text { steps } \\
\text { with the plantar surface of the forefoot off the } \\
\text { ground. }\end{array}$ & & & \\
\hline Gait & $\begin{array}{l}\text { Video and count percentage of toe walking } \\
\text { steps }\end{array}$ & $10 \%$ & & \\
\hline $\begin{array}{l}\text { Gross } \\
\text { motor }\end{array}$ & Gross motor ability (no formal measure) & $10 \%$ & & \\
\hline $\begin{array}{l}\text { Gross } \\
\text { motor }\end{array}$ & Functional difficulties that are task dependent & $10 \%$ & & \\
\hline $\begin{array}{l}\text { Gross } \\
\text { motor }\end{array}$ & Static or dynamic balance & $40 \%$ & & \\
\hline Gait & Gait analysis equipment within treatment space & $10 \%$ & & \\
\hline Gait & $\begin{array}{l}\text { Clinician modified version of Edinburgh gait } \\
\text { scale }\end{array}$ & $10 \%$ & & \\
\hline $\begin{array}{l}\text { Quality of } \\
\text { Life }\end{array}$ & Oxford Ankle Foot Questionnaire [23] & $10 \%$ & & \\
\hline
\end{tabular}

There were 72 parent participants consent in Study 2 with 34 parents providing data included for treatment outcome satisfaction. Table 2 provides the demographics of participants. All participants had one child who toe walked. 
Table 2

Demographics of parent participants and treatment opinions $(n=34)$

$N(\%)$

Median

(IQR)

Survey completed by mother of toe walking child

Country

United States of America (USA) and Canada

United Kingdom and Ireland

$8(19 \%)$

Australia and New Zealand

$8(22 \%)$

Other *

$3(9 \%)$

Number of children $<18$ years in family

$2(1$ to

3)

Age of child with toe walking gait

$\leq 5$ years

$8(24 \%)$

6 to 10 years

$>10$ years

$8(24 \%)$

Reason for toe walking gait

Idiopathic toe walking

Cerebral Palsy

Charcot Marie Tooth

Unknown or still under investigation

Health professionals were consulted in past 6 months for toe walking treatment

Pediatrician

Neurologist

Rehabilitation physician or physiatrist 


\begin{tabular}{|c|c|}
\hline & $\mathbf{N}(\%)$ \\
\hline & $\begin{array}{l}\text { Median } \\
\text { (IQR) }\end{array}$ \\
\hline Orthopaedic surgeon & $\begin{array}{l}20 \\
(59 \%)\end{array}$ \\
\hline Physiotherapist or physical therapist & $\begin{array}{l}23 \\
(68 \%)\end{array}$ \\
\hline Podiatrist & $6(18 \%)$ \\
\hline Orthotist & $5(15 \%)$ \\
\hline Occupational therapist & $\begin{array}{l}10 \\
(29 \%)\end{array}$ \\
\hline $\begin{array}{l}\text { Level of satisfaction relating to the questions health professionals aske } \\
\text { treatment progression }\end{array}$ & \\
\hline Very dissatisfied or dissatisfied & $9(26 \%)$ \\
\hline Neither satisfied nor dissatisfied & $3(9 \%)$ \\
\hline Satisfied or very satisfied & $\begin{array}{l}22 \\
(65 \%)\end{array}$ \\
\hline $\begin{array}{l}\text { Level of satisfaction relating to the assessment's health professionals } \\
\text { understand how treatment is progressing }\end{array}$ & \\
\hline Very dissatisfied or dissatisfied & $\begin{array}{l}16 \\
(47 \%)\end{array}$ \\
\hline Neither satisfied nor dissatisfied & $3(9 \%)$ \\
\hline Satisfied or very satisfied & $\begin{array}{l}15 \\
(44 \%)\end{array}$ \\
\hline Recommend treatments either undertaken, waitlisted or refused & \\
\hline Surgery for the calf, ankle or foot & $9(26 \%)$ \\
\hline Botulinum Toxin & $6(18 \%)$ \\
\hline Serial casting & $\begin{array}{l}17 \\
(50 \%)\end{array}$ \\
\hline Ankle foot orthoses, supramalleoli orthoses or full-length foot orthoses & $\begin{array}{l}19 \\
(56 \%)\end{array}$ \\
\hline Exercises to strengthen muscles & $\begin{array}{l}29 \\
(85 \%)\end{array}$ \\
\hline Stretches & $\begin{array}{l}27 \\
(79 \%)\end{array}$ \\
\hline
\end{tabular}


*Other includes India, Saudi Arabia, United Arab Emirates

There were 27 of the 34 parents provide opinions on the importance of the questions and assessments identified by health professionals. Figure 2 displays responses indicating most parents felt the domains were moderately or extremely important. There were seven comments on other outcome domains. These included additional commentary supporting some of the question such as fit and use of ankle foot orthoses, which would fit into the adherence question, pain at different parts of the body, which would fit in the pain questions and flexibility of the calf muscles, which would fit in the ankle range of motion assessments. Additional comments not fitting into the questions and assessments included balance, height of toe walking and participation in activities at home and school.

Parents who rated the questions or assessments as not at all important, or slightly important provided qualitative information about their responses. Four parents responded the amount of toe walking was not at all important, indicating they had accepted their child had a condition where toe walking would always be present and treatment was focused on minimizing its impact (e.g., their child had cerebral palsy). Two parents reflected being challenged if were asked to rate by a percentage and were concerned about how accurate it would be. Two of four parents still went on to agree the rating scale would be appropriate for some children who toe walked.

Four different parents indicated pain was not at all important, but reflected their responses were influenced by their child's absence of pain, one parent describing their child as "He was a happy toe walker ( $p 4)^{\prime \prime}$. Most parents ( $\mathrm{n}=3$ of 4 ) agreed with the use of the pain scales and anchor quests as present, the other remained neutral. One parent described ankle range was not at all important, as they experienced their child's measures fluctuating with growth and disease progression, yet they described the measures suggested by the health professionals being appropriate for other children who toe walked. This same parent responded similarly for strength and walking distance measures. An additional two parents also described their child never having difficulties with walking long distances and remained neutral on the use of a timed walk test.

Table 3 provides summary IAM and intention data about the self-use of questions and measures from parents who positively rated importance of these items. Parents provided refinement comments on wording or instructions on how to complete the scale. One parent expressed concern about selfmeasurement, indicating lack of training. Whereas two parents pondered if their child would get bored during the 6-minute walk test (6MWT). 
The final toe walking treatment core set of questions and measures are provided in Appendix 3. 
Table 3

Median (interquartile range (IQR)) scores from a 5 -point Likert scale $(0=$ Completely disagree to $4=$ Completely agree) from parents who viewed the domain as important using the IAM and intention

questions.

\begin{tabular}{|c|c|c|c|c|c|c|c|}
\hline $\begin{array}{l}\text { The scale or } \\
\text { assessment }\end{array}$ & $\begin{array}{l}\text { How } \\
\text { often } \\
\text { has } \\
\text { your } \\
\text { child } \\
\text { toe } \\
\text { walked } \\
\text { in the } \\
\text { last } \\
\text { week } \\
\text { n=19 } \\
\text { Median } \\
\text { (IQR) }\end{array}$ & $\begin{array}{l}\text { How } \\
\text { satisfied } \\
\text { you are } \\
\text { with the } \\
\text { amount } \\
\text { of toe } \\
\text { walking } \\
\text { your } \\
\text { child is } \\
\text { currently } \\
\text { doing } \\
\mathrm{n}=18 \\
\text { Median } \\
\text { (IQR) }\end{array}$ & $\begin{array}{l}\text { How well } \\
\text { you have } \\
\text { been able } \\
\text { to follow / } \\
\text { do any of } \\
\text { the } \\
\text { treatment } \\
\text { prescribed } \\
\mathrm{n}=19 \\
\text { Median } \\
\text { (IQR) }\end{array}$ & $\begin{array}{l}\text { Worst } \\
\text { pain } \\
\text { felt in } \\
\text { legs } \\
\text { today / } \\
\text { being } \\
\text { active } \\
\mathrm{n}=17 \\
\text { Median } \\
\text { (IQR) }\end{array}$ & $\begin{array}{l}\text { Measurement } \\
\text { of ankle } \\
\text { range of } \\
\text { movement } \\
\text { (picture of } \\
\text { weight } \\
\text { bearing } \\
\text { lunge) } \\
\mathrm{n}=17 \\
\text { Median (IQR) }\end{array}$ & $\begin{array}{l}\text { Use of } \\
\text { the } \\
\text { visual } \\
\text { gait } \\
\text { scale } \\
\text { with } \\
\text { score } \\
\text { of } 0-4 \\
n=16 \\
\text { Median } \\
\text { (IQR) }\end{array}$ & $\begin{array}{l}\text { Use of } \\
\text { a timed } \\
\text { walk } \\
\text { test for } \\
\text { velocity } \\
\text { (speed) } \\
\text { such } \\
\text { as the } \\
6- \\
\text { minute } \\
\text { walk } \\
\text { test } \\
\mathrm{n}=16 \\
\text { Median } \\
\text { (IQR) }\end{array}$ \\
\hline $\begin{array}{l}\text {...seems } \\
\text { fitting }\end{array}$ & $\begin{array}{l}4 \text { (3 to } \\
4)\end{array}$ & 3 (2 to 4$)$ & 3 (3 to 4$)$ & $\begin{array}{l}4 \text { (3 to } \\
4)\end{array}$ & 3 (3 to 4 ) & $\begin{array}{l}3 \text { (3 to } \\
4)\end{array}$ & $\begin{array}{l}3 \text { (3 to } \\
4)\end{array}$ \\
\hline $\begin{array}{l}\text { seems } \\
\text { suitable }\end{array}$ & $\begin{array}{l}4(4 \text { to } \\
4)\end{array}$ & 3 (2 to 4$)$ & 3 (3 to 4) & $\begin{array}{l}4 \text { (3 to } \\
4)\end{array}$ & 4 (2 to 4$)$ & $\begin{array}{l}3 \text { (3 to } \\
4)\end{array}$ & $\begin{array}{l}3 \text { (3 to } \\
4)\end{array}$ \\
\hline $\begin{array}{l}\text { seems } \\
\text { applicable }\end{array}$ & $\begin{array}{l}4 \text { (4) to } \\
4)\end{array}$ & 3 (2 to 4 ) & 3 (3 to 4 ) & $\begin{array}{l}3 \text { (3 to } \\
4)\end{array}$ & 4 (2 to 4$)$ & $\begin{array}{l}3 \text { (3 to } \\
4)\end{array}$ & $\begin{array}{l}3 \text { (3 to } \\
4)\end{array}$ \\
\hline $\begin{array}{l}\text { seems like a } \\
\text { good fit }\end{array}$ & $\begin{array}{l}4 \text { (3) to } \\
\text { 4) }\end{array}$ & 3 (2 to 4$)$ & 3 (2 to 4$)$ & $\begin{array}{l}4 \text { (3 to } \\
4)\end{array}$ & 4 (2 to 4$)$ & $\begin{array}{l}3 \text { (3 to } \\
4)\end{array}$ & $\begin{array}{l}3 \text { (3 to } \\
4)\end{array}$ \\
\hline \multicolumn{8}{|l|}{$\begin{array}{l}\text { Self- } \\
\text { completion } \\
\text { intention: }\end{array}$} \\
\hline $\begin{array}{l}\text { I could } \\
\text { complete this } \\
\text { question } \\
\text { about my } \\
\text { child and their } \\
\text { toe walking } \\
\text { without my } \\
\text { health } \\
\text { professional }\end{array}$ & $\begin{array}{l}4(4 \text { to } \\
4)\end{array}$ & 3 (2 to 4$)$ & 3 (2 to 4$)$ & $\begin{array}{l}3 \text { (3 to } \\
4)\end{array}$ & $\mathrm{N} / \mathrm{A}$ & N/A & $\mathrm{N} / \mathrm{A}$ \\
\hline $\begin{array}{l}\text { I could be } \\
\text { taught to do } \\
\text { the } \\
\text { measurement } \\
\text { in the picture } \\
\text { at home to } \\
\text { monitor my } \\
\text { child between } \\
\text { appointments }\end{array}$ & $\mathrm{N} / \mathrm{A}$ & $\mathrm{N} / \mathrm{A}$ & $\mathrm{N} / \mathrm{A}$ & $\mathrm{N} / \mathrm{A}$ & 4 (3 to 4 ) & $\begin{array}{l}4 \text { (3 to } \\
4)\end{array}$ & $\begin{array}{l}3 \text { (3 to } \\
4)\end{array}$ \\
\hline
\end{tabular}




\section{Discussion}

This is the first consensus-based set of outcome questions and assessments specifically collated for use during treatment for children with ITW. The expert health professionals considered measuring treatment outcomes through more domains than are typically captured within research about ITW treatment, such as understanding the parent satisfaction with treatment method, treatment adherence, daily or activitybased pain and ankle strength. Ankle range of motion measures are consistent within research studies about ITW [1], and the expert health professionals and parents agree with the importance of continuing to use these assessments. Gait velocity was also highlighted by health professionals and parents as important. Velocity is commonly collected in laboratory-based trials; however, this measure is rarely included in clinical audits or trials in health service environments [4]. This is despite a test such as the 6 minute walk test being inexpensive and reliable to complete, even with children under 10 years of age [21]. Despite parental concerns about the mundane nature of this assessment, we note the health professionals did not provide an alternative such as the 2-minute walk test (2MWT) [24]. This shorter version also has established normative values for children but may be limited in its ability to capture fatigue. All questions and assessments were strongly supported by parents of children being treated for ITW, while parents of children who toe walked for other reasons, also found most questions and measures appropriate.

This research is the first step to consistency in measuring treatment outcomes for ITW. The importance and variety of questions and assessments highlighted by the expert health professionals, in contrast to those in published research, may provide valuable insights into why some treatments report variable success. That is, the treatment may be reported as unsuccessful if the outcome measure is not sensitive enough to detect change, such as a binary construct of presence or absence of toe walking gait. Whereas, if alternate data were routinely collected, these may identify important outcomes which demonstrate treatment success to parents, such as resolution of pain or a child being able to walk faster during the treatment journey. The scales identified by health professionals and supported by parents could also enable the development of minimally important clinical differences across the difference questions and assessments. Visual analogue scales have long been used in this manner, and despite criticism, continue to perform well with the correct anchor questions [25]. For example, in the pain domains, most parents agreed with health professionals that pain should be collected during both physical activity and on the day of assessment rather than at just a singular time point. Collecting pain information at two timepoints may provide valuable indicators of the toe walking gait impact on the child's ability to participate with peers. Visual analogue scales are inexpensive and readily integrated into paper or electronic health records during active or inactive treatment.

There is commonly an element of inactive treatment during some point of the ITW treatment journey [15]. Inactive treatment or watching and waiting is commonly encouraged when a child toe walks without structural or functional impact [10]. Determining parents' support and willingness to be taught assessments may assist with home monitoring and this is a novel finding. Home monitoring provides opportunities to minimise health care wastage through shorter consultations that may be offered through 
telehealth. This could also be used within a monitoring portal with a parent uploading information and a clinician checking and providing feedback or an earlier appointment. Training parents as assessors in simple measures with known validity and reliability, such as the ankle weight bearing lunge, has demonstrated success for children with other foot conditions known to relapse [26]. The hesitancy in one parent's response highlights any implementation of any self-completion or assessment requiring parent training to be scaffolded with adequate support. There is little research known to the authors about supporting parents as physical assessors, but this novel finding should prompt further research with parents who wish to play this role during their child's health care journey.

The hybrid strength and range of motion scale developed by the research team and agreed on by the expert health professionals should be implemented with caution at this time. Despite the clinician researchers within the authorship the team informally trialing it within clinical settings during development, and parents supporting its use, it has not been subjected to rigorous testing. This is the next essential stage during implementation of this core set of outcome measures. That said, heel walking is a simple measure, and commonly utilised in paediatric musculoskeletal screening tools such as the peadiatric Gait Arms and Legs Screen (pGALS) [27]. Use of heel walking during these types of screening tools commonly prompts clinicians to record binary (able/unable) or qualitative observations of ability. Expert health professionals agreed that simple scaling of the forefoot position in relationship to the ground, to be both an indicator of the ankle range of motion and the strength of the foot dorsiflexor muscles. Both range and strength are known to be impacted with ongoing toe walking gait $[2,28]$. Future research should determine how reliably both clinicians and parents can score this scale in combination with the age that children can confidently undertake the heel walking task.

One limitation of this research was having parents indicate functional or participation tasks being important yet not indicated on the proforma or identified by the expert health professionals. This highlighted the importance of a core set of measures being underpinned by goal-based care. This is a clear limitation of our study. Goal based care enables parents and children to actively participate in treatment based on what is important to them, however, it does not always enable clinicians to understand any elements that may have factored into the reasoning of when the goal has not been achieved. Using scaled questions and assessment in combination with functional goals can assist clinical decisions. An additional limitation to this research was the expert health professionals being only located in Australia. We would counter that this core set of outcome measures are not uniquely Australian, nor are they worded in such a way that health professionals in other English speaking countries could not be able to apply these universally. We acknowledge some health services may require different tests to be performed based on culture or funding models. These simple, and inexpensive measures expert health professionals identified, and parents supported, could universally be adopted as the core set of measures, and region-specific sets could be an option if that were jurisdictionally required.

Lastly future research should also develop recommendations for optimal reassessment time frames. The majority of questions and scales within this core set may be collected at every appointment, however any timed walking tests may only be performed at key treatment direction changes or new goal setting. While 
all agreed that walking speed and endurance were important to collect, we did not consider asking health professionals on how often this could be clinically applied.

\section{Conclusion}

This research developed a core set of questions and measures clinicians, and researchers could implement during health care provision and any research with children who have ITW. Use of these measures will enable consistent data collection regardless of the setting and provide the foundation for large data pooling in future treatment research. While other outcome measures may be considered based on the aim of any research or health service requirements, we recommend this core set always be applied to enable consistently collected treatment outcome data.

\section{Abbreviations}

ITW

Idiopathic toe walking

SD

Standard deviation

6MWT

6 Minute Walk Test

2MWT

2 Minute Walk Test

\section{Declarations}

\section{Acknowledgements:}

The authors are grateful to the health professionals who generously gave their time through the multiple rounds of the Delphi study.

\section{Ethics approval and consent to participate}

The Sydney Children's Hospital's Network Human Research Ethics Committee (LNR/15/SCHN/296) and Monash University Human Research Ethics Committee (30310). Study 1 participants provided written informed consent. In Study 2, parent participants provided online informed consent. All methods were performed in accordance with the relevant guideline and regulations.

\section{Consent for publication}

No applicable

\section{Availability of data and materials}


The datasets generated and analysed are available from the corresponding author on reasonable request. The proforma is provided within manuscript.

\section{Competing interests}

The authors declare they have no competing interests.

\section{Author's contributions}

KG and CMW conceived and designed Study 1. KG and CMW contributed to the Delphi survey design, data collection and analysis. KG, VP, AC, DP and CMW contributed to the development of the survey for Study 2 and data collection with parents. KG and CMW undertook data analysis. KG, VP, AC, DP and CMW contributed to the interpretation of the data. KG and CMW drafted the manuscript, VP, AC and DP provided critical revisions. All authors approved the current manuscript version of the manuscript for publication and agree to be accountable for personal contribution and ensure research accuracy and integrity.

\section{Funding}

CMW was supported through Study 1 with a National Health and Medical Research Council Early Career Health Professional Research Fellowship. This research did not receive any specific grant from funding agencies in the public, commercial, or not-for-profit sectors.

\section{References}

1. Caserta AJ, Pacey V, Fahey M, Gray K, Engelbert RH, Williams CM: Interventions for idiopathic toe walking. Cochrane Database Syst Rev 2019, 10:CD012363.

2. Alvarez C, De Vera M, Beauchamp R, Ward V, Black A: Classification of idiopathic toe walking based on gait analysis: development and application of the ITW severity classification. Gait Posture 2007, 26(3):428-435.

3. Engström P, Tedroff K: Idiopathic Toe-Walking: Prevalence and Natural History from Birth to Ten Years of Age. J Bone Joint Surg Am 2018, 100(8):640-647.

4. Caserta $A$, Morgan $P$, Williams $C$ : Identifying methods for quantifying lower limb changes in children with idiopathic toe walking: a systematic review. Gait Posture 2019, 67:181-186.

5. Williams $\mathrm{CM}$, Tinley $\mathrm{P}$, Curtin $\mathrm{M}$, Nielsen S: Vibration perception thresholds in children with idiopathic toe walking gait. J Child Neurol2012, 27(8):1017-1021.

6. Williams CM, Tinley P, Curtin M, Wakefield S, Nielsen S: Is idiopathic toe walking really idiopathic? The motor skills and sensory processing abilities associated with idiopathic toe walking gait. $J$ Child Neuro/2014, 29(1):71-78.

7. Fanchiang HD, Geil M: The effects of walking surface and vibration on the gait pattern and vibration perception threshold of typically developing children and children with idiopathic toe walking. Georgia: Georgia State University; 2014. 
8. Engström P, Bartonek $\AA$, Tedroff K, Orefelt C, Haglund-Åkerlind Y, Gutierrez-Farewik EM: Botulinum toxin $A$ does not improve the results of cast treatment for idiopathic toe-walking: a randomized controlled trial. J Bone Joint Surg Am 2013, 95(5):400-407.

9. Engstrom P, Van't Hooft I, Tedroff K: Neuropsychiatric symptoms and problems among children with idiopathic toe-walking. J Pediatr Orthop 2012, 32(8):848-852.

10. Stricker SJ, Angulo JC: Idiopathic toe walking: a comparison of treatment methods. J Pediatr Orthoped 1998, 18(3):289-293.

11. Herrin K, Geil M: A comparison of orthoses in the treatment of idiopathic toe walking: A randomized controlled trial. Prosthet Orthot Int 2016, 40(2):262-269.

12. Michalitsis J, Murphy AT, Rawicki B, Haines TP, Williams C: Full length foot orthoses have an immediate treatment effect and modify gait of children with idiopathic toe walking. Gait Posture 2019, 68:227-231.

13. Eastwood DM, Menelaus D, Dickens RV, Broughton NS, Cole WG: Idiopathic Toe-Walking: Does treatment alter the natural history? J Pediatr Orthoped $B$ 2000, 9(1):47-49.

14. van Kuijk AA, Kosters $R$, Vugts $M$, Geurts AC: Treatment for idiopathic toe walking: a systematic review of the literature. Journal of rehabilitation medicine: official journal of the UEMS European Board of Physical and Rehabilitation Medicine 2014, 46(10):945-957.

15. Williams CM, Gray K, Davies N, Barkocy M, Fahey M, Simmonds J, Accardo P, Eastwood D, Pacey V: Exploring health professionals' understanding of evidence-based treatment for idiopathic toe walking. Child Care Health Dev 2020, 46(3):310-319.

16. Eichinger K, Burns J, Cornett K, Bacon C, Shepherd ML, Mountain J, Sowden J, Shy R, Shy ME, Herrmann DN: The Charcot-Marie-Tooth Functional Outcome Measure (CMT-FOM). Neurology 2018, 91(15):e1381-e1384.

17. Morgan EM, Munro JE, Horonjeff J, Horgan B, Shea B, Feldman BM, Clairman H, Bingham CO, Thornhill S, Strand V: Establishing an updated core domain set for studies in juvenile idiopathic arthritis: a report from the OMERACT 2018 JIA Workshop. The Journal of rheumatology 2019, 46(8):1006-1013.

18. Weiner BJ, Lewis CC, Stanick C, Powell BJ, Dorsey CN, Clary AS, Boynton MH, Halko H: Psychometric assessment of three newly developed implementation outcome measures. Implementation science: IS 2017, 12(1):108.

19. Bennell KL, Talbot RC, Wajswelner $\mathrm{H}$, Techovanich W, Kelly $\mathrm{DH}$, Hall AJ: Intra-rater and inter-rater reliability of a weight-bearing lunge measure of ankle dorsiflexion. Aust J Physiother 1998, 44(3):175-180.

20. Evans AM, Scutter SD: Sagittal plane range of motion of the pediatric ankle joint: A reliability study. Journal of the American Podiatric Medical Association 2006, 96(5):418-422.

21. Lammers AE, Hislop AA, Flynn Y, Haworth SG: The 6-minute walk test: normal values for children of 4-11 years of age. Archives of disease in childhood 2008, 93(6):464-468. 
22. Evans AM, Scutter SD: Sagittal plane range of motion of the pediatric ankle joint: a reliability study. Journal of the American Podiatric Medical Association, 96(5):418-422.

23. Morris C, Doll HA, Wainwright A, Theologis T, Fitzpatrick R: The Oxford ankle foot questionnaire for children: scaling, reliability and validity. The Journal of bone and joint surgery British volume 2008, 90(11):1451-1456.

24. Li AM, Yin J, Au JT, So HK, Tsang T, Wong E, Fok TF, Ng PC: Standard reference for the six-minutewalk test in healthy children aged 7 to 16 years. American journal of respiratory and critical care medicine 2007, 176(2):174-180.

25. Garra G, Singer AJ, Domingo A, Thode HC, Jr.: The Wong-Baker pain FACES scale measures pain, not fear. Pediatric emergency care 2013, 29(1):17-20.

26. Gosse G, Ward E, McIntyre A, Banwell HA: The reliability and validity of the weight-bearing lunge test in a Congenital Talipes Equinovarus population (CTEV). PeerJ 2021, 9:e10253.

27. Foster H, Kay L, Friswell M, Coady D, Myers A: Musculoskeletal screening examination (pGALS) for school-age children based on the adult GALS screen. Arthritis Care \& Research 2006, 55(5):709-716.

28. De Oliveira V, Arrebola L, De Oliveira P, Yi L: Investigation of Muscle Strength, Motor Coordination and Balance in Children with Idiopathic Toe Walking: A Case-control Study. Dev Neurorehabil 2021:1-7.

\section{Figures}

\section{Gait scale}

Ask the child 'Can you try to walk on your heels?'

You may wish to demonstrate as well.

Observe child walking for 10 steps.

\begin{tabular}{|l|l|l|l|l|}
\hline & & & & \\
\hline
\end{tabular}

Figure 1 
Hybrid gait scale considering heel height, ankle range of motion and strength

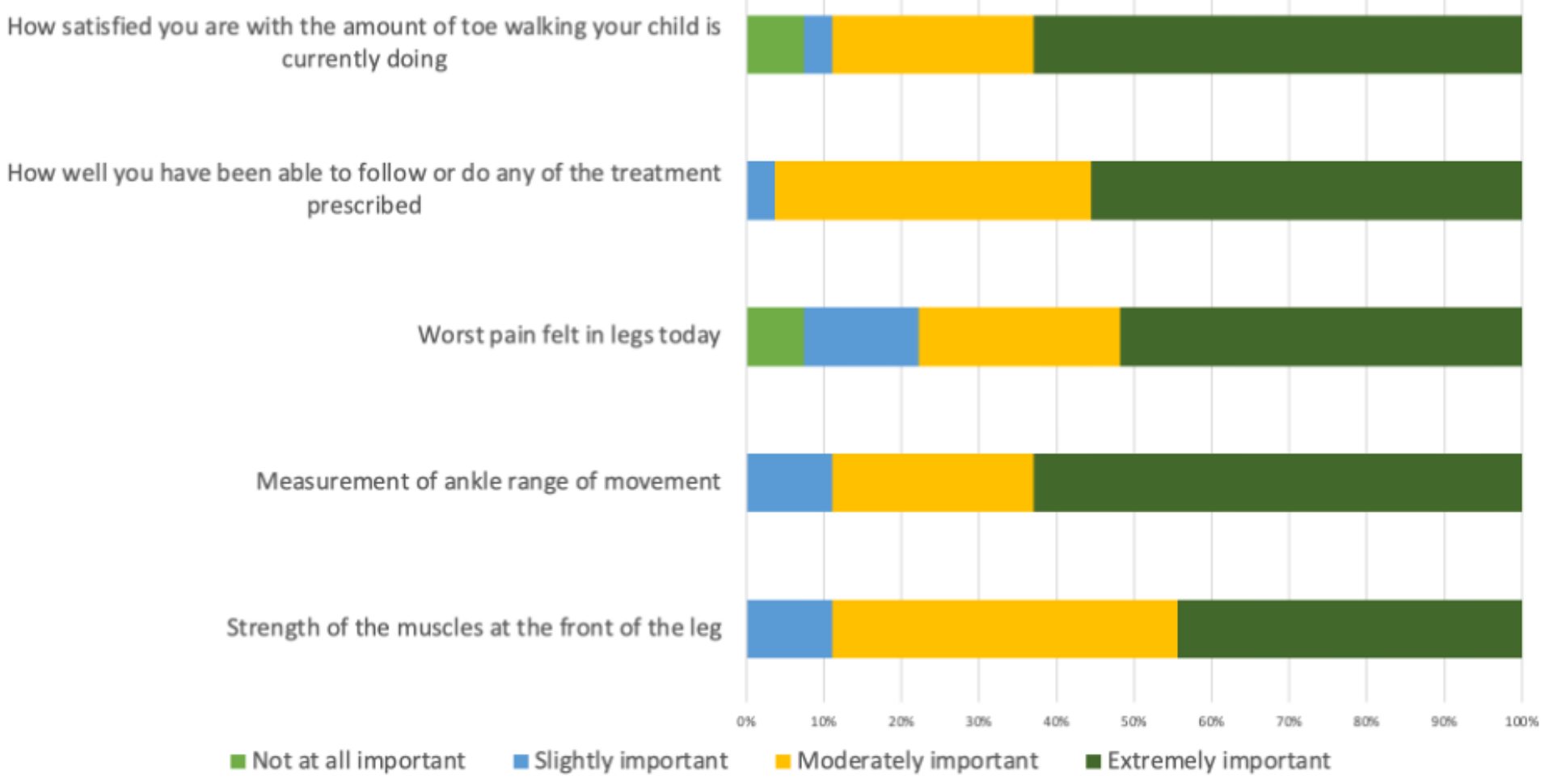

How often your child toe walked in the last week

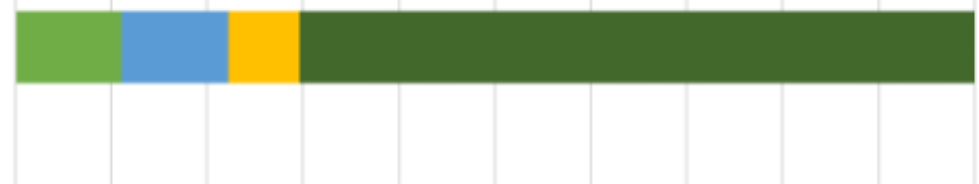

Figure 2

Parent rated level of importance ascribed to domains identified by health professionals.

\section{Supplementary Files}

This is a list of supplementary files associated with this preprint. Click to download.

- Appendix1.DelphiSurveyRound1Questions.pdf

- Appendix2.Parentsurvey.pdf

- Appendix3.ITWTOP.docx 